\title{
Risk Assessment of Intermittent and Continuous Nasogastric Enteral Feeding Methods in Adult Inpatients: A Meta-Analysis
}

\author{
Guang Yang $\mathbb{D}^{1,2}$ Bojun Zheng, ${ }^{1}$ and Yi Yu ${ }^{1}$ \\ ${ }^{1}$ Department of Critical Care Medicine, The Second Affiliated Hospital of Guangzhou University of Chinese Medicine, \\ Guangzhou 510006, Guangdong, China \\ ${ }^{2}$ Guangzhou University of Chinese Medicine, Guangzhou 510006, Guangdong, China \\ Correspondence should be addressed to Guang Yang; yangguang@gzucm.edu.cn
}

Received 14 September 2020; Revised 13 November 2020; Accepted 23 December 2020; Published 7 January 2021

Academic Editor: Zhaohui Liang

Copyright (c) 2021 Guang Yang et al. This is an open access article distributed under the Creative Commons Attribution License, which permits unrestricted use, distribution, and reproduction in any medium, provided the original work is properly cited.

Diarrhea and pneumonia are common and serious complications in hospitalized patients requiring nasogastric enteral feeding. Our study aimed to compare the risk of diarrhea and pneumonia between intermittent nasogastric enteral feeding (IEF) and continuous nasogastric enteral feeding (CEF). We systematically searched PubMed, Web of Science, and Cochrane for relevant articles published from August 9, 1992, to September 1, 2019. A total of 637 IEF and CEF patients were included in our metaanalysis. Odds ratios (ORs) with associated $95 \%$ confidence intervals (CIs) were calculated to estimate the effects of diarrhea and pneumonia. We showed that hospital patients that required IEF had an increased risk of diarrhea compared with CEF. In the subgroup analyses, similar conclusions were identified in the non-China group and small sample size group (size $<100)$. However, our results showed no significant differences in the China group or large sample size group (size $\geq 100$ ). Furthermore, our analysis showed that no significant association was observed for the risk of pneumonia between IEF and CEF patients. For inpatients requiring nasogastric enteral feeding, $\mathrm{CEF}$ is a better method of enteral nutrition compared with IEF, of which patients experience a significantly increased risk of diarrhea.

\section{Introduction}

Nutritional support is one of the indispensable factors for human survival. At present, enteral nutrition (EN) is the preferred way of nutritional support for severe patients with diminished intestinal function, especially in the Intensive Care Unit (ICU). Enteral provision of caloric intake favorably modulates disease severity $[1,2]$, immune system function [3], gastrointestinal integrity [4], and mucosal host defenses [5]. EN can be given as intermittent nasogastric enteral feeding (IEF) or continuous nasogastric enteral feeding (CEF) [6, 7]. CEF is thought to be better tolerated by patients with limited absorptive gut surface area or gastrointestinal dysfunction but is associated with more tube clogging and requires the patient to be attached to an infusion pump $[7,8]$. IEF is given at standard intervals and is considered to be more physiological with regard to the cephalic phase of digestion and gut homeostasis [9]. However, many researchers believe that IEF could increase the risk of developing gastrointestinal and pulmonary complications when compared to $\operatorname{CEF}[6,10]$.

For patients requiring nasogastric enteral feeding to maintain dysphagia and poor oral intake, their length of hospital stay and quality of life are uncertain [11]. It is essential to prevent complications from nasogastric enteral feeding. Diarrhea is the most common complication in nasogastric enteral feeding, and aspiration of gastric contents often results in a higher risk of pneumonia, which is one of the most common causes of death in tube-fed patients. Therefore, many studies have been conducted in search of ways to best prevent these complications [12-15]. However, there is still controversy with the current research.

Thereby, the aim of the present study was to investigate the risk of diarrhea and pneumonia in IEF and CEF patients from relevant studies to provide a better nutritional feeding method for patients with clinical nasogastric feeding to improve comfort and increase quality of life. 


\section{Materials and Methods}

2.1. Search Strategy. Systematic literature in electronic literature databases was searched for relevant prospective published studies prior to September 1, 2019. Potentially relevant studies were identified by various combinations of the following terms or keywords: "intermittent nasogastric enteral feeding," "continuous nasogastric enteral feeding," "pneumonia," and/or "diarrhea." However, we excluded case reports, editorials or letters to the editor, review articles, and non-English studies. The latest study was published between April and June 2011.

2.2. Study Selection Criteria. To ensure the reliability of the studies, inclusion criteria were as follows: (1) observational studies with patients with nasogastric tube enteral feeding at least once a day; (2) all studies emphasizing comparison of complications caused by IEF versus CEF; (3) studies providing an accurate number of patients with diarrhea or pneumonia during the investigation; and (4) adult patients $\geq 18$ years old. Included studies satisfied all four inclusion criteria.

Studies were excluded if they met any of the following characteristics: (1) being designed as a review, a casecontrolled study, or an animal study; (2) patient age being $<18$ years old; (3) being not associated with diarrhea or pneumonia; and (4) overlapped or duplicate reports.

2.3. Data Extraction. For each of the selected studies, the following items were extracted: authors, year of publication, study regions, mean age, sample size, duration of follow-up, quality scores, and endpoints. The endpoints of the studies included the number of patients that developed diarrhea or pneumonia with IEF and CEF over the study period. We assessed the quality of the studies obtained from the literature search using the Newcastle-Ottawa Scale (NOS). A total score of $\geq 7$ was considered high quality.

2.4. Statistical Analysis. Stata version 12.0 (Stata Corporation) was used to perform all statistical analyses. Incidences of diarrhea and pneumonia during IEF and CEF for each study were treated as dichotomous outcomes and expressed as odds ratios (ORs) and accompanying 95\% confidence intervals (CIs). We assessed heterogeneity among studies using Cochrane's $Q$ and $I^{2}$ tests. A fixed-effect model was used if no significant heterogeneity was identified $\left(I^{2}=0.0 \%\right)$ or the random effect model was used.

Considering inconsistent patient characteristics, different methods for IEF, and other confounding factors across studies, we performed sensitivity analysis to evaluate the stability of our results and explored the possible sources of heterogeneity. Potential publication bias was detected by visually inspecting the funnel plots and using the Begg and Egger tests. Because of the small number of studies and patients for other outcomes, we conducted sensitivity analysis and publication bias assessment only for diarrhea and pneumonia in IEF. A two-sided value of $P<0.05$ was considered statistically significant.

\section{Results}

3.1. Literature Search and Included Studies. Detailed instructions of how the studies were obtained are presented in Figure 1. Through the outlined search strategy, we identified 271 papers that were deemed potentially eligible. A total of 183 full-text papers were selected following title and abstract screening, of which 166 were subsequently excluded (Figure 1). We included nine articles $[6,10,15-21]$ in the present meta-analysis after the application of the selection criteria. Two studies [17, 20-21] were recognized for inclusion which were only related to diarrhea, and two $[16,19]$ studies were only related to pneumonia; the remaining five articles $[6,10,15,18]$ included both diarrhea and pneumonia.

The trials included 637 patients with a critical illness, trauma, head-injury, older tube-fed, and mechanical ventilation $[6,10,15-21]$. The characteristics of the individual studies are shown in Table 1. There were two endpoints from the nine studies, including the number of patients with diarrhea $[6,10,15,17,18,20-21]$ and the number of patients with pneumonia during IEF and CEF $[6,10,15,16,18-20]$.

The study size ranged from 18 to 178 patients, and the duration varied between one and 28 days. Nasogastric enteral feeding periods spanned from 1992 to 2011 . These trials were all observational studies and were conducted in the USA [6, 10, 15, 16], Hong Kong, China [17, 20], Brazil [18], India [21], and Poznań, Poland [19]. For all the studies, the average age of the patients was $>18$ years old. Availability of ORs with their $95 \%$ CIs was obtained by statistical analysis. According to the NOS, all studies were of great quality and had scores of seven or more.

3.2. Diarrhea in IEF and CEF. Seven studies including 537 patients documented diarrhea occurrence in patients during IEF and CEF $[6,10,15,17,18,20,21]$. We observed that IEF increased the risk of diarrhea compared with CEF in hospitals $(\mathrm{OR}=3.10,95 \% \mathrm{CI}=1.55-1.69, P=0.496$, random effects, Figure 2). Meanwhile, we performed two subgroup analyses according to the study region (China and nonChina; Figure 3$)$ and sample size $(\geq 100$ and $<100$; Figure 4$)$. In comparison with overall research results, similar conclusions were identified in the non-China group $(\mathrm{OR}=4.71$, 95\% CI $=1.93-11.50, P=0.561$, random effects, Figure 3 ). However, metaregression showed no significant differences in the China group $(\mathrm{OR}=1.37,95 \% \mathrm{CI}=0.42-4.55$, $P=0.635$, random effects, Figure 3$)$. In the small sample size group $(<100)$, there was an increased risk of diarrhea in IEF patients compared with $\mathrm{CEF}$ patients $(\mathrm{OR}=3.69,95 \%$ $\mathrm{CI}=1.63-8.35, P=0.295$, random effects, Figure 4). However, the analysis indicated no significant differences in the large sample size group $(\geq 100 ; \quad O R=1.92, \quad 95 \%$ $\mathrm{CI}=0.51-7.23, P=0.800$, random effects, Figure 4$)$. Differences between study region and sample size subgroups were not statistically significant $\left(I^{2}=0.0 \%, \quad P=0.496\right.$; Figure 2). 


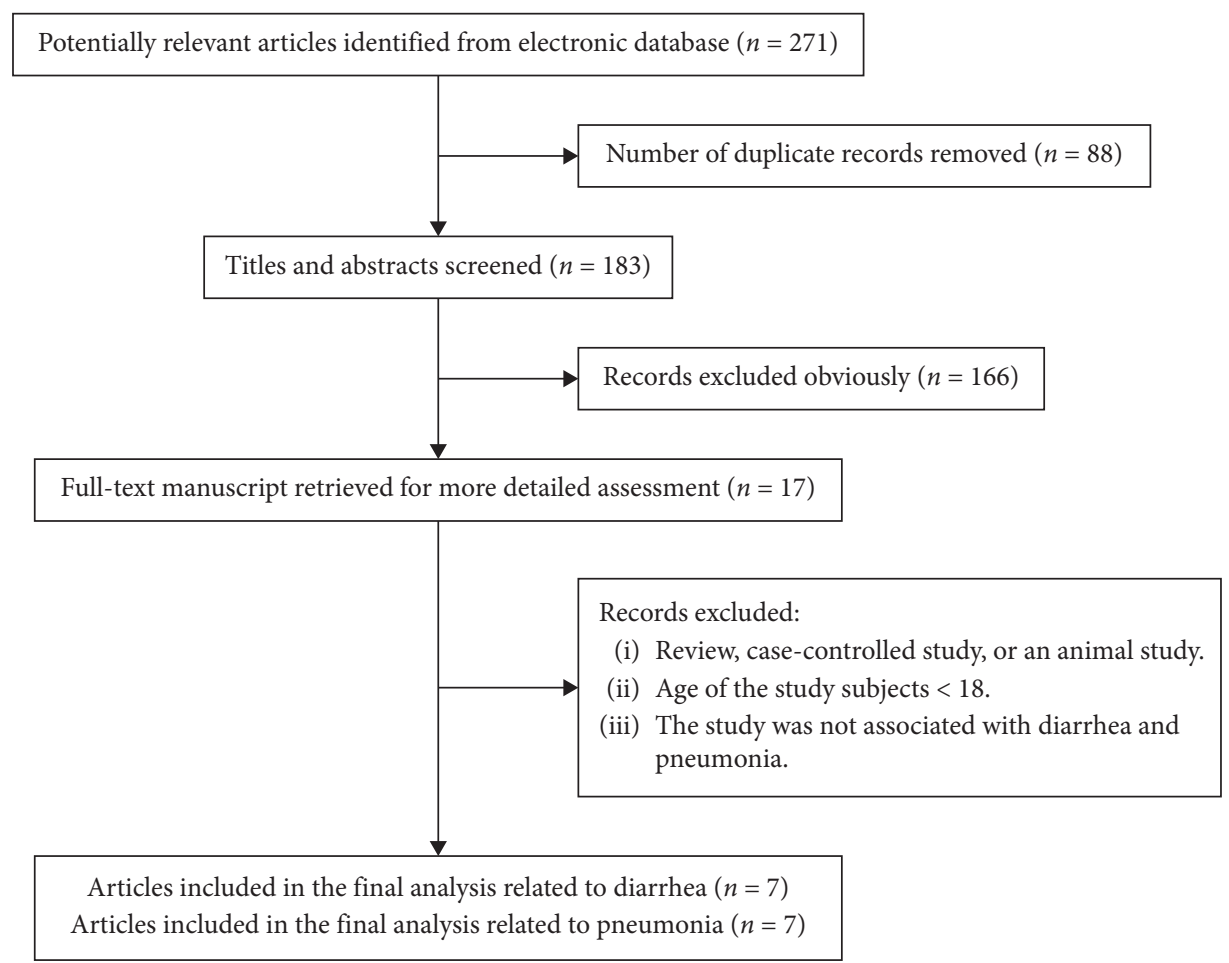

FIgURE 1: Flow diagram of literature search and study selection.

TABLE 1: Main characteristics of the included studies.

\begin{tabular}{|c|c|c|c|c|c|c|c|c|c|}
\hline Study (year) & Country & Sample & $\begin{array}{l}\text { Mean } \\
\text { age } \\
\text { (years) }\end{array}$ & $\begin{array}{l}\text { Diarrhea } \\
\text { in IEF }\end{array}$ & $\begin{array}{l}\text { Diarrhea } \\
\text { in } \mathrm{CEF}\end{array}$ & $\begin{array}{l}\text { Pneumonia } \\
\text { in IEF }\end{array}$ & $\begin{array}{l}\text { Pneumonia } \\
\text { in CEF }\end{array}$ & $\begin{array}{c}\text { Follow- } \\
\text { up } \\
\text { (days) }\end{array}$ & $\begin{array}{c}\text { Quality } \\
\text { (Newcastle-Ottawa } \\
\text { Scale) }\end{array}$ \\
\hline $\begin{array}{l}\text { Jerry o. Ciocon } \\
\text { (1992) }\end{array}$ & USA & 60 & 72 & 29 & 20 & 10 & 5 & 7 & 8 \\
\hline $\begin{array}{l}\text { Marc J. M (only } \\
\text { pneumonia) } \\
(1996)\end{array}$ & USA & 60 & 66.5 & & & 2 & 0 & 3 & 7 \\
\hline $\begin{array}{l}\text { Emmy C. (2002) } \\
\text { Jenny Shun Wah }\end{array}$ & $\begin{array}{l}\text { USA } \\
\text { Hong }\end{array}$ & 18 & 36.6 & 5 & 2 & 1 & 0 & 7 & 7 \\
\hline $\begin{array}{l}\text { Lee (only } \\
\text { diarrhea) (2003) }\end{array}$ & $\begin{array}{l}\text { Kong, } \\
\text { China }\end{array}$ & 74 & 82.05 & 6 & 5 & & & 5 & 8 \\
\hline $\begin{array}{l}\text { Letícia Faria } \\
\text { Serpa }(2003)\end{array}$ & Brazil & 28 & 67.25 & 3 & 0 & 0 & 1 & 3 & 8 \\
\hline $\begin{array}{l}\text { Jana B. A. (2007) } \\
\text { Barbara }\end{array}$ & USA & 139 & 46.52 & 5 & 3 & 38 & 33 & 7 & 7 \\
\hline $\begin{array}{l}\text { Tamowicz (only } \\
\text { pneumonia) } \\
(2007)\end{array}$ & $\begin{array}{l}\text { Poznań, } \\
\text { Poland }\end{array}$ & 40 & $18-75$ & & & 4 & 7 & 6 & 8 \\
\hline $\begin{array}{l}\text { J. S. W. Lee (only } \\
\text { diarrhea) (2010) }\end{array}$ & $\begin{array}{l}\text { Hong } \\
\text { Kong, } \\
\text { China }\end{array}$ & 178 & Over 60 & 1 & 0 & 14 & 12 & 28 & 8 \\
\hline $\begin{array}{l}\text { Indubala Maurya } \\
\text { (only diarrhea) } \\
(2011)\end{array}$ & India & 40 & 40.45 & 2 & 0 & & & 1 & 8 \\
\hline
\end{tabular}

IEF: intermittent nasogastric enteral feeding; CEF: continuous nasogastric enteral feeding. 


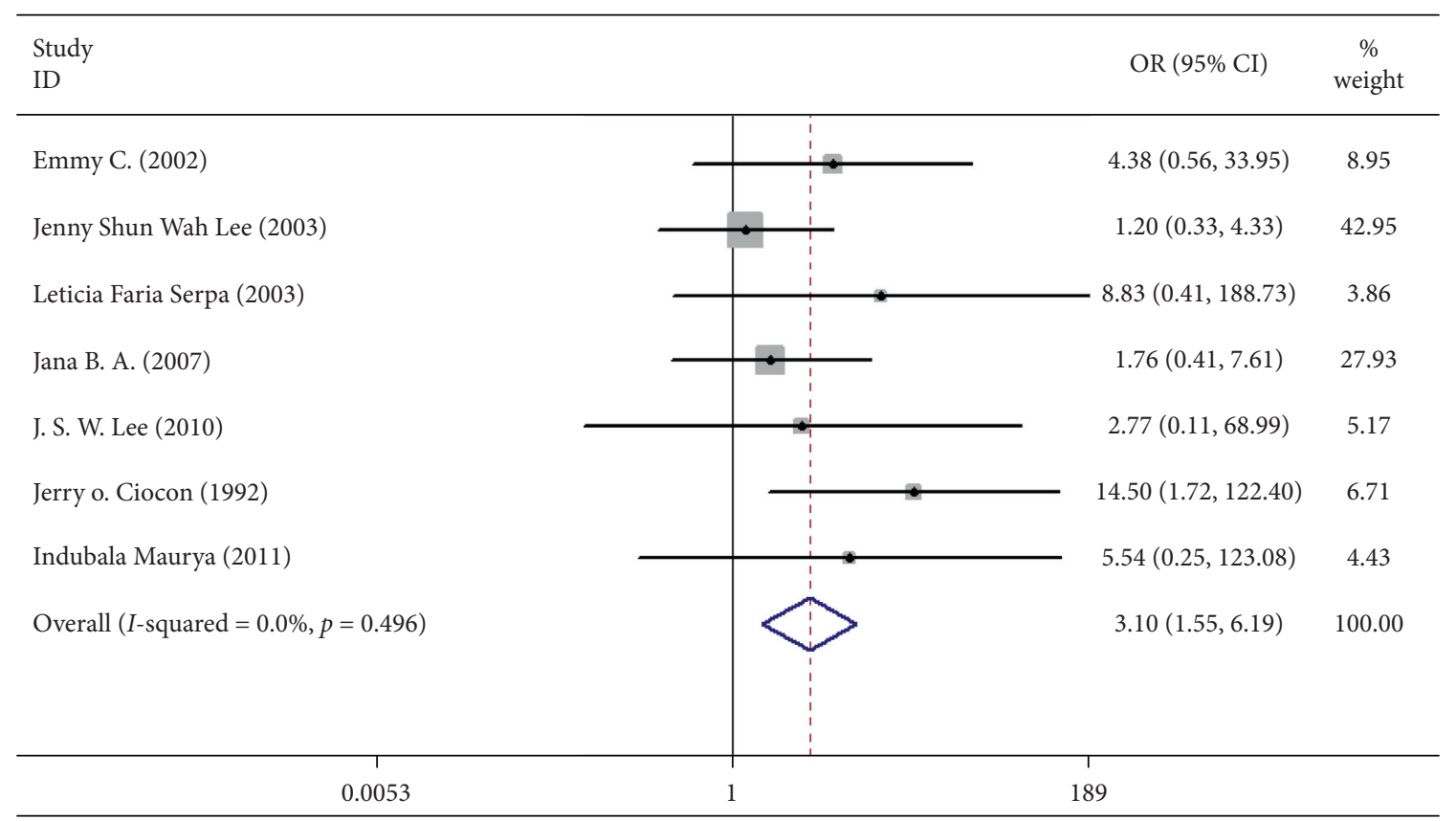

Figure 2: Result of meta-analysis on odds ratio (OR) values for diarrhea. Each square denotes the ORs for each trial comparison with the corresponding $95 \%$ confidence intervals (CIs).

\begin{tabular}{|c|c|c|}
\hline $\begin{array}{l}\text { Study } \\
\text { ID }\end{array}$ & OR $(95 \% \mathrm{CI})$ & $\begin{array}{c}\% \\
\text { weight }\end{array}$ \\
\hline Non-China & & \\
\hline Emmy C. (2002) & $4.38(0.56,33.95)$ & 8.95 \\
\hline Leticia Faria Serpa (2003) & $8.83(0.41,188.73)$ & 3.86 \\
\hline Jana B. A. (2007) & $1.76(0.41,7.61)$ & 27.93 \\
\hline Jerry o. Ciocon (1992) & $14.50(1.72,122.40)$ & 6.71 \\
\hline Indubala Maurya (2011) & $5.54(0.25,123.08)$ & 4.43 \\
\hline Subtotal $(I$-squared $=0.0 \%, p=0.561)$ & $4.71(1.93,11.50)$ & 51.88 \\
\hline China & & \\
\hline Jenny Shun Wah Lee (2002) & $1.20(0.33,4.33)$ & 42.95 \\
\hline J. S. W. Lee (2010) & $2.77(0.11,68.99)$ & 5.17 \\
\hline Subtotal $(I$-squared $=0.0 \%, p=0.635)$ & $1.37(0.42,4.45)$ & 48.12 \\
\hline Overall $(I$-squared $=0.0 \%, p=0.496)$ & $3.10(1.55,6.19)$ & 100.00 \\
\hline 0.0053 & \multicolumn{2}{|l|}{189} \\
\hline
\end{tabular}

FIGURE 3: Result of meta-analysis on odds ratio (OR) values for diarrhea. The subgroup is analyzed according to the study region (China and non-China). Each square denotes the ORs for each trial comparison with the corresponding 95\% confidence intervals (CIs). 


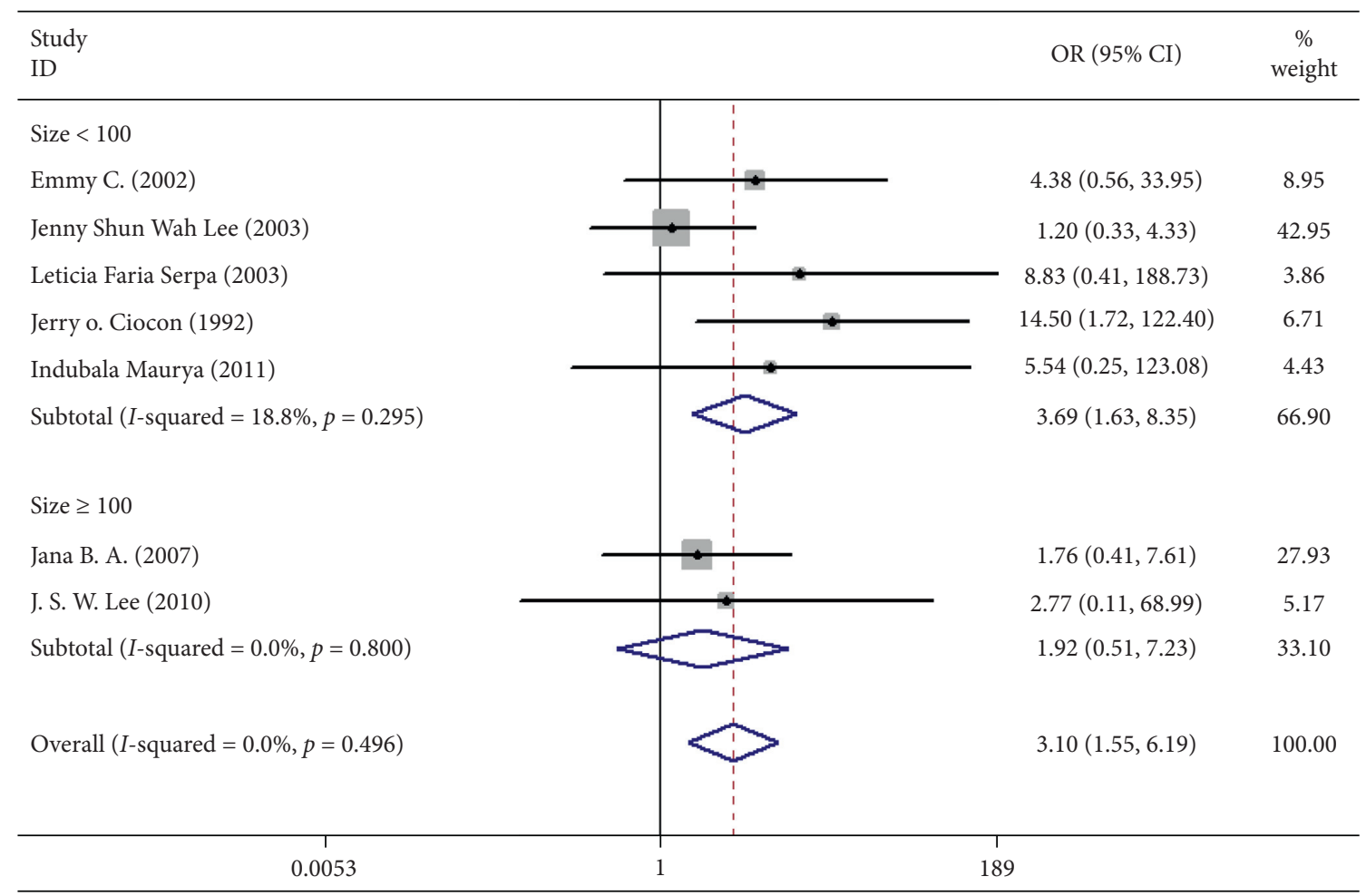

FIGURE 4: Result of meta-analysis on odds ratio (OR) values for diarrhea. The subgroup is analyzed according to the sample size (size $\geq 100$ and size $<100)$. Each square denotes the ORs for each trial comparison with the corresponding 95\% confidence intervals (CIs).

3.3. Sensitivity Analysis for the Risk of Diarrhea. We performed a sensitivity analysis aiming to test the stability of our results. We found no significant differences between the outcomes among all trials, and we did not observe any significant interactions with a range from 0.93 to 5.63 (Figure 5). Furthermore, there was no evident publication bias by funnel plots (Figures 6 and 7).

3.4. Pneumonia in IEF and CEF. Mortality data were available from seven trials $(n=523)[6,10,15-16,18-20]$. The combined results showed that no statistically significant association was identified for the risk of pneumonia between IEF and CEF patients $(\mathrm{OR}=1.28,95 \% \mathrm{CI}=0.84-1.94$, $P=0.527$, random effects, Figure 8 ). In addition, we performed subgroup analyses according to the sample size of the patient population (large $\geq 100$ and small $<100$ groups; Figure 9). Similar conclusions were identified between the small sample size group $(\mathrm{OR}=1.35,95 \% \mathrm{CI}=0.63-2.92$, $P=0.294$, random effects, Figure 9) and large size group $(\mathrm{OR}=1.24,95 \% \mathrm{CI}=0.75-2.05, P=0.674$, random effects, Figure 9 ). In addition, we performed a sensitivity analysis on these studies and found no significant differences between overall research results, and no notable interactions were observed with a range from 0.67 to 2.11 (Figure 10). Furthermore, no evident publication bias was found using funnel plots (Figures 11 and 12).

One study [15] was performed in China, and we compared this study with the remaining six studies that were performed in other countries. We observed a similar result as the overall seven $[6,10,15-16,18-20]$ studies $(O R=1.35$,
95\% CI $=0.83-2.91, P=0.423$, random effects, Figure 13). Hence, we suggest that there is no difference in the risk of pneumonia between the two nasogastric enteral feeding methods.

\section{Discussion}

Nutrition plays a significant role in medical institutions. For patients requiring nasogastric enteral feeding, malnutrition can have fatal effects. The American Society of Parenteral Enteral Nutrition (ASPEN) published the 2016 Edition of the Guidelines for the Provision and Evaluation of Nutritional Support Therapy for Adult Critically Ill Patients [22], which suggested nasogastric enteral feeding is preferred for inpatients requiring nutritional support therapy. Enteral nutrition supply and feeding through the stomach is an acceptable enteral nutrition for most patients requiring nasogastric feeding, and it is recommended that the intestinal nutrition tolerance should be monitored daily to avoid inappropriate termination of enteral nutrition. At present, there are a few studies on feeding methods in clinical practice. Hospitals mainly provide enteral nutrition in two ways, including IEF and CEF. Our meta-analysis focused on determining which method is more scientific and humane.

According to various studies, CEF maintains the relative sterility of the nutrient solution, stability of food osmotic pressure, avoids contamination, and reduces many related complications $[6,10]$. Additionally, IEF has a certain extent of security and rationality $[6,10]$. Current studies have already indicated that there is no correlation between gastric 


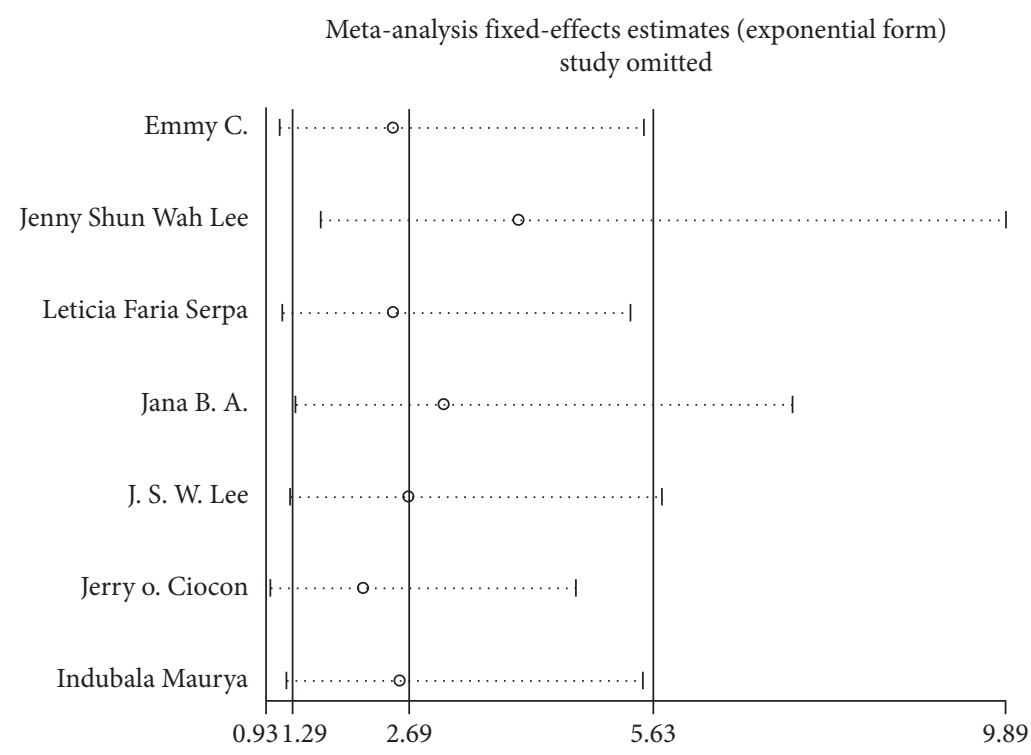

FIgURE 5: Result of sensitivity analysis for diarrhea. The middle vertical line indicates the combined OR, and the two vertical lines represent the $95 \% \mathrm{CI}=$ values. Every hollow round indicates the pooled OR when the left study was omitted in a meta-analysis.

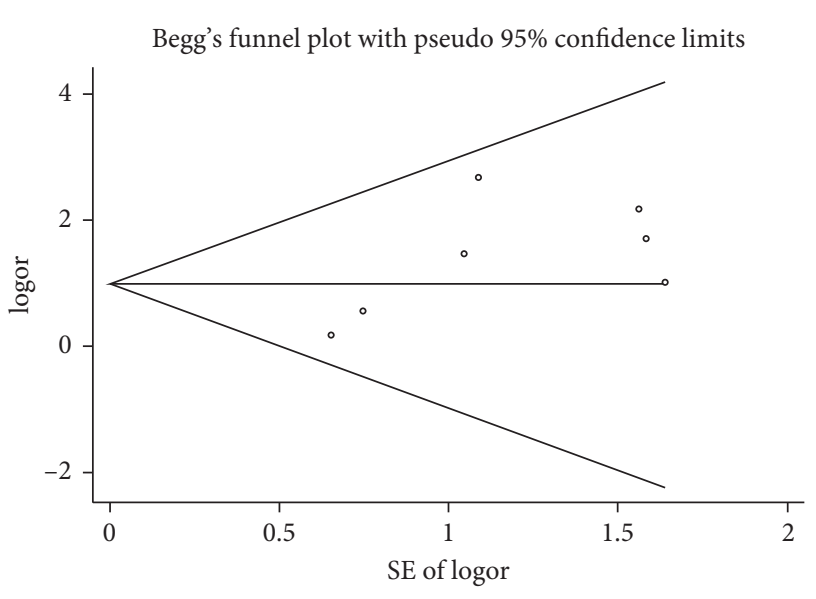

FIGURE 6: Begg's funnel plot with pseudo 95\% confidence limits.

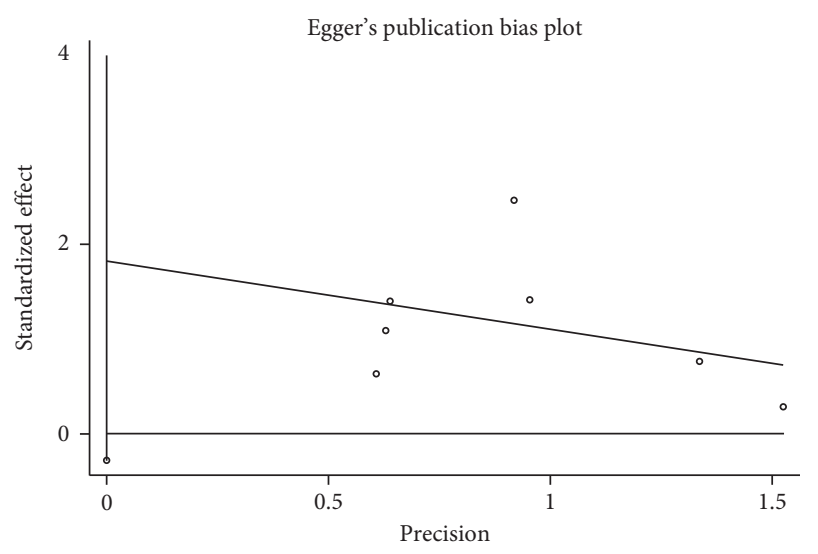

FIGURE 7: Egger's publication bias plot.

contents and reflux aspiration when the residual amount in the stomach is $<500 \mathrm{ml}$ [23-25]. Therefore, the IEF method with an intermittent nutrient solution of approximately
$500 \mathrm{ml}$ is safe and suitable for physiological and clinical needs. However, many researchers believe that IEF could increase the risk of developing gastrointestinal and pulmonary complications [12-15]. To determine the risk factors between IEF and CEF, we conducted a meta-analysis that included nine studies $[6,10,15-21]$ (seven studies related to diarrhea and six studies that included pneumonia).

The present study showed that patients had a higher risk of developing diarrhea using the IEF method $[6,10,15,17,18,20,21]$. Because our meta-analysis results should be interpreted cautiously, we carried out a subgroup analysis. We found that most studies (non-China and small sample size groups) resulted in similar conclusions when compared with the overall study results. However, it is important to note that there was no significant difference in the China group and the large sample size group $(\geq 100)$. Although sensitivity and heterogeneity analysis showed that the results for risk of developing diarrhea were not dominated by individual studies, our meta-analysis results remain interesting.

There is no evidence that a significant association exists between the risk of pneumonia in IEF or CEF patients. There are several possible explanations for why the risk of pneumonia between IEF and CEF is not significant. Tracheobronchial aspiration of gastric contents is a recognized risk factor for pneumonia in the critically ill and the elderly. However, the rate of gastroesophageal regurgitation was not different between IEF and CEF in a previous study [26]. In addition, Simme et al. showed that the stomach is rarely a reservoir of pathogens causing pneumonia; therefore, IEF with a high gastrointestinal tract complication rate does not indicate a high incidence of pneumonia [27]. A previous study has demonstrated that CEF is a risk factor for stomach colonization with potentially pathogenic microorganisms due to an increase in stomach $\mathrm{pH}$ instead of IEF [28]. However, the exact incidence of pneumonia is difficult to 


\begin{tabular}{|c|c|c|c|}
\hline $\begin{array}{l}\text { Study } \\
\text { ID }\end{array}$ & & OR $(95 \% \mathrm{CI})$ & $\begin{array}{c}\% \\
\text { weigh }\end{array}$ \\
\hline Emmy C (2002) & 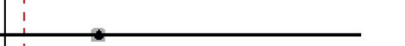 & $3.35(0.12,93.83)$ & 1.09 \\
\hline Leticia Faria Serpa (2003) & & $0.31(0.01,8.29)$ & 3.73 \\
\hline BARBARA TAMOWICZ (2007) & & $0.46(0.11,1.94)$ & 14.42 \\
\hline Jana B. A. (2007) & & $1.35(0.72,2.52)$ & 43.55 \\
\hline JERRY O. (1992) & $\rightarrow$ & $2.50(0.74,8.50)$ & 8.58 \\
\hline MARC J. M. BONTEN (1996) & 1 & $5.35(0.25,116.31)$ & 1.18 \\
\hline J. S. W. Lee (2010) & & $1.08(0.47,2.48)$ & 27.43 \\
\hline Overall $(I$-squared $=0.0 \%, p=0.527)$ & & $1.28(0.84,1.94)$ & 100.00 \\
\hline $\begin{array}{c}\mid \\
0.0085\end{array}$ & $\begin{array}{c}1 \\
115\end{array}$ & & \\
\hline
\end{tabular}

FIGURE 8: Result of meta-analysis on odds ratio (OR) values for pneumonia. Each square denotes the ORs for each trial comparison with the corresponding $95 \%$ confidence intervals (CIs).

\begin{tabular}{|c|c|c|}
\hline $\begin{array}{l}\text { Study } \\
\text { ID }\end{array}$ & OR $(95 \% \mathrm{CI})$ & $\begin{array}{c}\% \\
\text { weight }\end{array}$ \\
\hline Size $<100$ & & \\
\hline Emmy C (2002) & $3.35(0.12,93.83)$ & 1.09 \\
\hline Leticia Faria Serpa (2003) & $0.31(0.01,8.29)$ & 3.73 \\
\hline BARBARA TAMOWICZ (2007) & $0.46(0.11,1.94)$ & 14.42 \\
\hline JERRY O. (1992) & $2.50(0.74,8.50)$ & 8.58 \\
\hline MARC J. N. BONTEN (1996) & $5.35(0.25,116.31)$ & 1.18 \\
\hline Subtotal $(I$-squared $=19.0 \%, p=0.294)$ & $1.35(0.63,2.92)$ & 29.02 \\
\hline \multicolumn{3}{|l|}{ Size $\geq 100$} \\
\hline Jana B. A. (2007) & $1.35(0.72,2.05)$ & 43.55 \\
\hline J. S. W. Lee (2010) & $1.08(0.47,2.48)$ & 27.43 \\
\hline Subtotal $(I$-squared $=0.0 \%, p=0.674)$ & $1.24(0.75,2.05)$ & 70.98 \\
\hline Overall $(I$-squared $=0.0 \%, p=0.527)$ & $1.28(0.84,1.94)$ & 100.00 \\
\hline 0.0086 & & \\
\hline
\end{tabular}

Figure 9: Result of meta-analysis on odds ratio (OR) values for pneumonia. The subgroup is analyzed according to the sample size (size $\geq 100$ and size $<100$ ). Each square denotes the ORs for each trial comparison with the corresponding 95\% confidence intervals (CIs).

interpret from our selected articles as these were shortduration studies $[6,10,15-16,18-19]$, which is one of the limitations in our meta-analysis.

The current systematic review and meta-analysis article has several limitations. One potential limitation is the large time span in the included studies. Excessive differences in research years ranging from 1992 to 2011 could cause deviations in results because of the development of nursing technology, treatment technology, and materials used. In addition, the follow-up duration and the difference in the 


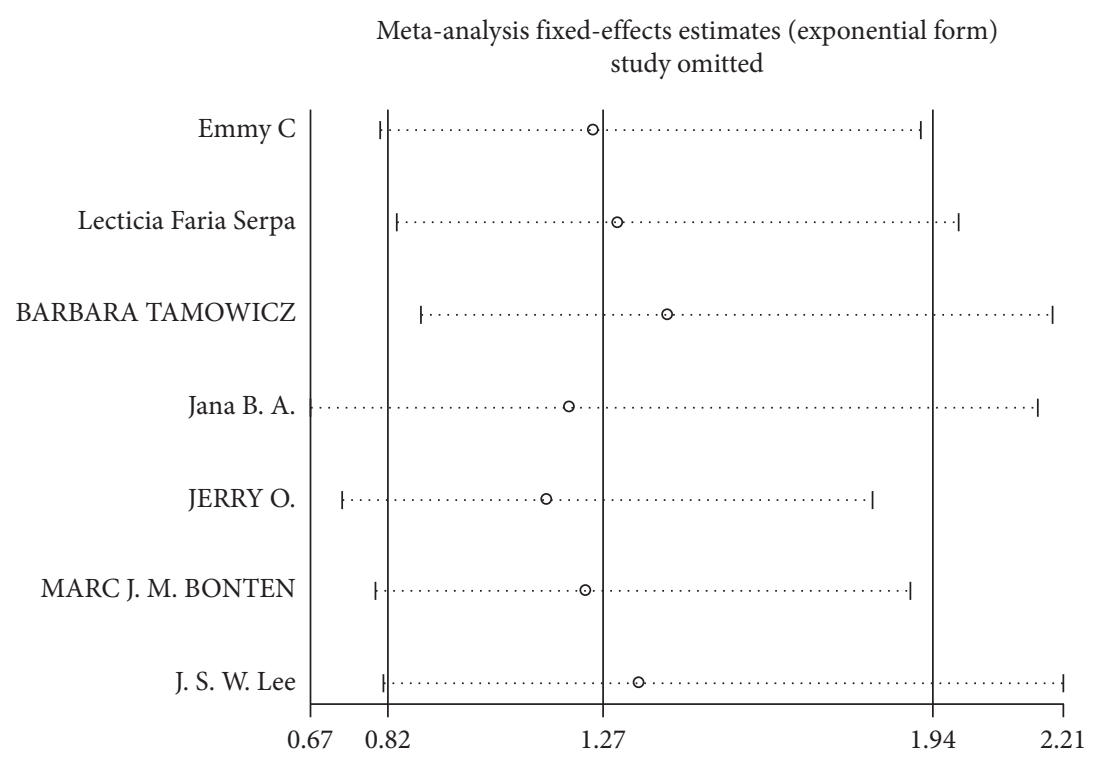

FIGURE 10: Result of sensitivity analysis for pneumonia. The middle vertical line indicates the combined OR, and the two vertical lines represent the $95 \% \mathrm{CI}=$ values. Every hollow round indicates the pooled OR when the left study was omitted in a meta-analysis.

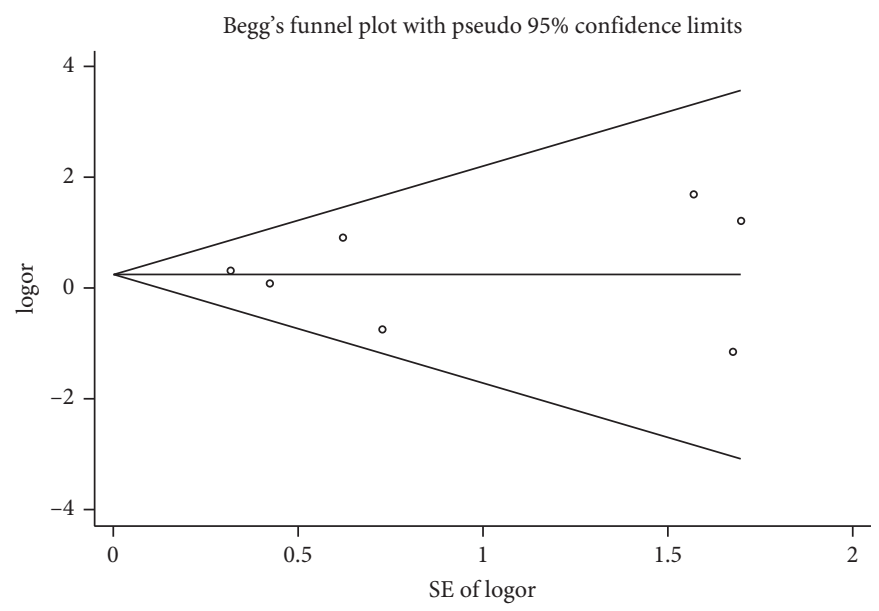

FIGURE 11: Begg's funnel plot with pseudo $95 \%$ confidence limits.

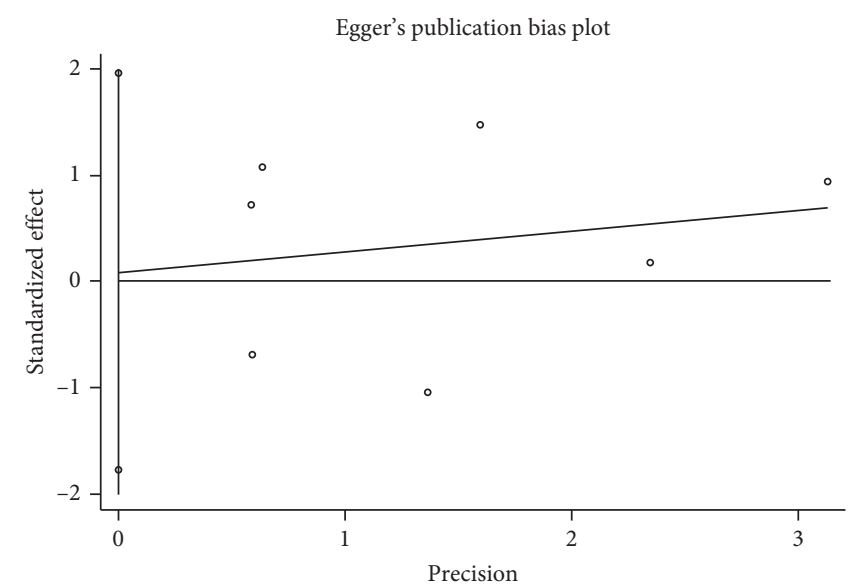

Figure 12: Egger's publication bias plot. 


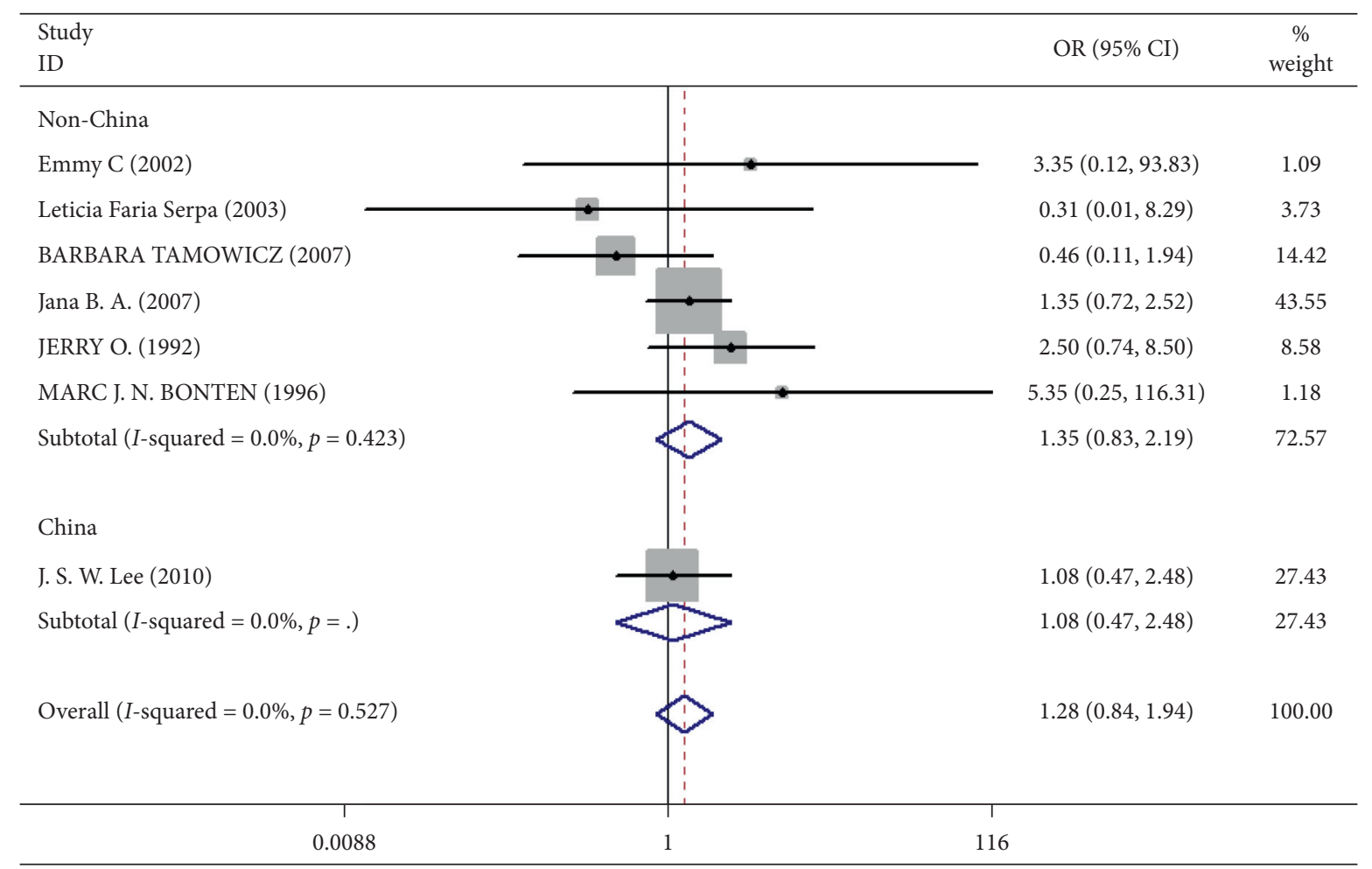

FIGURE 13: Result of meta-analysis on odds ratio (OR) values for pneumonia. The subgroup is analyzed according to the study region (China and non-China). Each square denotes the ORs for each trial comparison with the corresponding 95\% confidence intervals (CIs).

study population may lead to heterogeneity. However, we were not able to detect a major source of heterogeneity in the subgroup and sensitivity analyses.

\section{Conclusion}

In conclusion, IEF patients experienced a significantly increased risk of diarrhea and no evidence of an increased risk of pneumonia compared with CEF patients. Therefore, CEF is a better method of nasogastric enteral feeding for hospital inpatients.

\section{Disclosure}

Guang Yang, Bojun Zheng, and Yi Yu are the co-first authors.

\section{Conflicts of Interest}

The authors declare no conflicts of interest.

\section{Acknowledgments}

The authors would like to thank all authors of the included studies in their meta-analysis. This work was supported by grants from Guangdong Provincial Key Laboratory of Research on Emergency in TCM (no. 2017B030314176), National Natural Science Foundation of China (no: 82004317), Clinical Research Project of Guangdong Provincial Hospital of Traditional Chinese Medicine (no: YN10101908), and the
Specialized Research on Traditional Chinese Medicine Science and Technology in Guangdong Provincial Hospital of Traditional Chinese Medicine (no. YN2014PJ R203).

\section{References}

[1] A. C. J. Windsor, S. Kanwar, A. G. K. Li et al., "Compared with parenteral nutrition, enteral feeding attenuates the acute phase response and improves disease severity in acute pancreatitis," GUT, vol. 42, no. 3, pp. 431-435, 1998.

[2] S. J. Taylor, S. B. Fettes, C. Jewkes, and R. J. Nelson, "Prospective, randomized, controlled trial to determine the effect of early enhanced enteral nutrition on clinical outcome in mechanically ventilated patients suffering head injury," Critical Care Medicine, vol. 27, no. 11, pp. 2525-2531, 1999.

[3] K. A. Kudsk, M. A. Croce, T. C. Fabian et al., "Enteral versus parenteral feeding effects on septic morbidity after blunt and penetrating abdominal trauma," Annals of Surgery, vol. 215, no. 5, pp. 503-513, 1992.

[4] H. Saito, O. Trocki, J. Alexander, R. Kopcha, T. Heyd, and S. Joffe, "The effect of route of nutrient administration on the nutritional state, catabolic hormone secretion, and gut mucosal integrity after burn injury," Journal of Parenteral and Enteral Nutrition, vol. 11, no. 1, pp. 1-7, 1987.

[5] J. Alverdy, H. S. Chi, and G. F. Sheldon, "The effect of parenteral nutrition on gastrointestinal immunity," Annals of Surgery, vol. 202, no. 6, pp. 681-684, 1985.

[6] J. O. Ciocon, D. J. Galindo-Ciocon, C. Tiessen, and D. Galindo, "Continuous compared with intermittent tube feeding in the elderly," Journal of Parenteral and Enteral Nutrition, vol. 16, no. 6, pp. 525-528, 1992. 
[7] D. H. Rhoney, D. Parker, C. M. Formea, C. Yap, and W. M. Coplin, "Tolerability of bolusversuscontinuous gastric feeding in brain-injured patients," Neurological Research, vol. 24, no. 6, pp. 613-620, 2002.

[8] B. A. Griggs and M. G. Hoppe, "Update nasogastric tube feeding," AJN, American Journal of Nursing, vol. 79, no. 3, pp. 481-485, 1979.

[9] A. Sanz París, J. Lázaro, A. Guallar, P. Gracia, A. Caverni, and R. Albero, "Nutrición enteral continua frente a nutrición en bolo: efectos sobre el péptido $\mathrm{C}$ urinario y el balance nitrogenado," Medicina Clínica, vol. 124, no. 16, pp. 613-615, 2005.

[10] E. C. Steevens, A. F. Lipscomb, G. V. Poole, and G. S. Sacks, "Comparison of continuous vs intermittent nasogastric enteral feeding in trauma patients: perceptions and practice," Nutrition in Clinical Practice, vol. 17, no. 2, pp. 118-122, 2002.

[11] D. Volkert, A. M. Beck, T. Cederholm et al., "ESPEN guideline on clinical nutrition and hydration in geriatrics," Clinical Nutrition, vol. 38, no. 1, pp. 10-47, 2019.

[12] N. A. Metheny, "Preventing respiratory complications of tube feedings: evidence-based practice," American Journal of Critical Care, vol. 15, no. 4, pp. 360-369, 2006.

[13] J. S. Scolapio, "Methods for decreasing risk of aspiration pneumonia in critically ill patients," Journal of Parenteral and Enteral Nutrition, vol. 26, no. 6, pp. S58-S61, 2002.

[14] E. Shang, N. Geiger, J. W. Sturm, and S. Post, "Pump-assisted enteral nutrition can prevent aspiration in bedridden percutaneous endoscopic gastrostomy patients," Journal of Parenteral and Enteral Nutrition, vol. 28, no. 3, pp. 180-183, 2004.

[15] J. B. A. MacLeod, J. Lefton, D. Houghton et al., "Prospective randomized control trial of intermittent versus continuous gastric feeds for critically ill trauma patients," The Journal of Trauma: Injury, Infection, and Critical Care, vol. 63, no. 1, pp. 57-61, 2007.

[16] M. J. Bonten, C. A. Gaillard, R. van der Hulst et al., "Intermittent enteral feeding: the influence on respiratory and digestive tract colonization in mechanically ventilated intensive-care-unit patients," American Journal of Respiratory and Critical Care Medicine, vol. 154, no. 2, pp. 394-399, 1996.

[17] J. S. W. Lee and T. W. Auyeung, "A comparison of two feeding methods in the alleviation of diarrhoea in older tube-fed patients: a randomised controlled trial," Age and Ageing, vol. 32, no. 4, pp. 388-393, 2003.

[18] L. F. Serpa, M. Kimura, J. Faintuch, and I. Ceconello, "Effects of continuous versus bolus infusion of enteral nutrition in critical patients," Revista do Hospital das Clínicas, vol. 58, no. 1, pp. 9-14, 2003.

[19] T. Barbara, M. Adam, and M. Grzymisławski, “The influence of the feeding therapy model on pulmonary complications in patients treated under conditions of intensive therapy," Advances in Clinical and Experimental Medicine, vol. 16, pp. 365-373, 2007.

[20] J. S. W. Lee, T. Kwok, P. Y. Chui et al., "Can continuous pump feeding reduce the incidence of pneumonia in nasogastric tube-fed patients? A randomized controlled trial," Clinical Nutrition, vol. 29, no. 4, pp. 453-458, 2010.

[21] R. Garg, R. Sood, I. Maurya, M. Pawar, and M. Kaur, "Comparison of respiratory quotient and resting energy expenditure in two regimens of enteral feeding-continuous vs. intermittent in head-injured critically ill patients," Saudi Journal of Anaesthesia, vol. 5, no. 2, p. 195, 2011.

[22] N. M. Mehta, H. E. Skillman, S. Y. Irving et al., "Guidelines for the provision and assessment of nutrition support Therapy in the pediatric critically ill patient," Pediatric Critical Care Medicine, vol. 18, no. 7, pp. 675-715, 2017.

[23] S. A. McClave, J. K. Lukan, J. A. Stefater et al., "Poor validity of residual volumes as a marker for risk of aspiration in critically ill patients," Critical Care Medicine, vol. 33, no. 2, pp. 324-330, 2005.

[24] J. Reignier, E. Mercier, A. Le Gouge, T. Boulain, A. Desachy et al., "Effect of not monitoring residual gastric volume on risk of ventilator-associated pneumonia in adults receiving mechanical ventilation and early enteral feeding," JAMA, vol. 309, no. 3, pp. 249-256, 2013.

[25] J. C. Montejo, E. Miñambres, L. Bordejé et al., "Gastric residual volume during enteral nutrition in ICU patients: the REGANE study," Intensive Care Medicine, vol. 36, no. 8, pp. 1386-1393, 2010.

[26] T. E. Bowling, B. Cliff, J. W. Wright, P. E. Blackshaw, A. C. Perkins, and D. N. Lobo, "The effects of bolus and continuous nasogastric feeding on gastro-oesophageal reflux and gastric emptying in healthy volunteers: a randomised three-way crossover pilot study," Clinical Nutrition, vol. 27, no. 4, pp. 608-613, 2008.

[27] H. H. Simms, E. DeMaria, L. McDonald, D. Peterson, A. Robinson, and K. W. Burchard, "Role of gastric colonization in the development of pneumonia in critically 111 trauma patients," The Journal of Trauma: Injury, Infection, and Critical Care, vol. 31, no. 4, pp. 531-537, 1991.

[28] M. J. M. Bonten, C. A. Gaillard, F. H. van Tiel, S. V. Der Geest, and E. E. Stobberingh, "Continuous enteral feeding counteracts preventive measures for gastric colonization in intensive care unit patients," Critical Care Medicine, vol. 22, no. 6, pp. 939-944, 1994. 